\title{
Diagnosis and Treatment of Sciatica in the Netherlands: A Survey among Neurologists and Anesthesiologists
}

\author{
Bastiaan ter Meulen ${ }^{\mathrm{a}, \mathrm{b}} \quad$ Caroliene Overweg $^{\mathrm{a}}$ Thomas Feenstra $^{\mathrm{a}}$ \\ Brigitte Brouwer $^{c}$ Michel Terheggen ${ }^{d}$ Hanneke van Dongen ${ }^{e}$ \\ Jan Willem Kallewaard ${ }^{d, f}$ Raymond Ostelo ${ }^{b, e}$ Henry Weinstein ${ }^{a, g}$
}

${ }^{a}$ Department of Neurology, OLVG Teaching Hospital, Amsterdam, The Netherlands; ${ }^{b}$ Department of Epidemiology and Data Science, Amsterdam Movement Sciences Research Institute, VUMC, Vrije Universiteit Amsterdam, Amsterdam, The Netherlands; ' Department of Anesthesiology and Pain Treatment, Maastricht University Medical Center, Maastricht, The Netherlands; ${ }^{d}$ Department of Anesthesiology and Pain Treatment, Rijnstate Hospital, Arnhem, The Netherlands; 'Department of Health Sciences, Amsterdam Movement Sciences Research Institute, Faculty of Science, Vrije Universiteit Amsterdam, Amsterdam, The Netherlands; ${ }^{f}$ Department of Anesthesiology and Pain Treatment, Amsterdam University Medical Center, Amsterdam, The Netherlands; ${ }^{9}$ Department of Neurology, Amsterdam UMC, Amsterdam, The Netherlands

\section{Keywords}

Sciatica · Lower back pain · Neurology · Anesthesiology ·

Opioids · Epidural steroid injections

\begin{abstract}
Background: This study aimed to assess how Dutch neurologists and anesthesiologists diagnose and treat people with sciatica in secondary care and to evaluate their adherence to the newest guidelines. Methods: We conducted a cross-sectional survey. Respondents were asked about their current clinical practice related to sciatica. Three authors rated the respondents' adherence to the guidelines on a three-point Likert scale. Results: Eighty neurologists and 44 anesthesiologists completed the questionnaire. Neurologists diagnose their sciatica patients primarily using a magnetic resonance imaging (89\%). Selective diagnostic nerve blocks are considered useful by $81 \%$ of the neurologists. Neurologists primarily treat patients with pain medication, and $40 \%$ of
\end{abstract}

them think epidural steroid injections are effective in 40$60 \%$ of injected patients. Twenty-nine percent of neurologists refer patients to a neurosurgeon after 4 months. Anesthesiologists consider a selective diagnostic nerve root block to have a higher diagnostic value than mapping. The most reported side effect of epidural injections is exacerbation of pain (82\%). Pulse radiofrequency is applied in $9-11 \%$ of acute cases. The results also indicate that Dutch neurologists and anesthesiologists follow an evidence-based approach that is strictly or broadly in line with the guideline. Conclusions: Neurologists treat sciatica patients initially with pain medication and physiotherapy, followed by epidural steroid injections and referral for surgery. Anesthesiologists treat sciatica patients with one or more steroid injections or may perform a selective nerve root block. Imaging, selective nerve root blocks, medication, physiotherapy, and pulse radiofrequency are topics of further research.

(c) 2021 S. Karger AG, Basel karger@karger.com

www.karger.com/ene
(C) 2021 S. Karger AG, Basel
Correspondence to:

Bastiaan ter Meulen, bas.termeulen@olvg.nl

\section{Karger}




\section{Introduction}

Sciatica, or lumbosacral radiculopathy, is defined as pain, radiating from the back into the leg. Patients may also report sensory symptoms or weakness [1]. In about $85 \%$ of cases, sciatica is caused by a herniated lumbar disc with nerve root compression [2]. In the Netherlands, the mean incidence rate and prevalence rate of sciatica have been estimated at 9.4 and 17.2 per 1,000 person years, respectively [3]. About half of the patients with sciatica recover within a year $[4,5]$.

In the Netherlands, patients with sciatica are primarily treated by general practitioners. According to the Dutch general practitioners' guideline [6], treatment of sciatica consists of pain treatment by analgesics if needed, referral to physiotherapy, and the advice to maintain, or resume, normal daily activities as much as possible. If patients do not recover within 6 weeks, they are referred to a secondary care for further diagnosis and treatment. In the Netherlands, $16 \%$ of sciatica patients are referred to a secondary care, of which $70 \%$ to a neurologist and $14 \%$ to an anesthesiologist [7]. In secondary care, diagnostic procedures include magnetic resonance imaging (MRI) and selective diagnostic nerve root blocks. Treatments include medication, therapeutic epidural corticosteroid injections, and surgery in cases of long-lasting and severe pain or dysfunction.

The management of sciatica in secondary care varies considerably within and between countries. For example, there is significant variation in the use of epidural steroid injections between different US states [8] and referral to physiotherapy between Denmark and the Netherlands [9]. These differences may be due to a paucity of evidence on the value of interventions and a lack of clear clinical guidelines, or they may reflect differences in healthcare and insurance systems [10].

We aimed to assess how Dutch neurologists and anesthesiologists diagnose and treat patients with sciatica. Our study coincides with the launch of the updated Dutch multidisciplinary guideline on sciatica [11]. This study might therefore identify important gaps between the updated evidence-based recommendations and daily practice, thereby identifying important areas for future clinical studies.

\section{Methods}

\section{Design}

We conducted a cross-sectional survey among Dutch neurologists and anesthesiologists. The results of our study were reported in accordance with the Checklist for Reporting Results of Internet E-Surveys (CHERRIES) [12].

\section{Participant Recruitment}

From February 27, 2020 to April 1, 2020, neurologists and anesthesiologists were recruited: (1) by contacting the program directors of the major neurology residency programs in the Netherlands directly and asking them and (through them) their residents and staff members and their colleagues from the anesthesiology (pain) department to participate in the current study; (2) through the 12 members of the Pain Section of the Dutch Society for Neurology, all of whom were asked to participate and to invite their direct inhospital colleagues; (3) through "snowballing," meaning that participants were asked to invite other neurologists and anesthesiologists for participation. For neurologists to be eligible, they had to see at least 1 patient with sciatica a week. This inclusion criterion was not applied for anesthesiologists because they were assumed to treat $>1$ sciatica patient a week. Eventually, 260 general neurologists (including 68 residents) and 75 anesthesiologists specialized in pain medicine were invited to participate. This was done through email. We sent 2 reminders, including a reminder 1 week after the initial invitation and another 1 after 2 weeks. The total period during which the questionnaires could be completed was 5 weeks.

\section{Content of the Questionnaire}

The survey was developed using a 3-step procedure: first, separate provisional questionnaires were developed for neurologists and anesthesiologists by a neurologist (BTM), an anesthesiologist (JWK), and an epidemiologist (RO). The survey for neurologists contained 32 general questions and 3 hypothetical cases with 64 questions. The survey for anesthesiologists contained 25 general questions and 3 hypothetical cases with 52 corresponding questions; second, the provisional questionnaires were pilot-tested and modified, where necessary; third, the final questionnaires were administered using Castor Electronic Data Capture. The final questionnaires can be found in online suppl. File 1; for all online suppl. material, see www.karger.com/doi/10.1159/000515578. There were no incentives offered to the participants.

\section{Analyses}

The findings of the surveys were analyzed using descriptive statistics. Continuous variables were described using means and standard deviations, and categorical data were described using frequencies and percentages.

To assess guideline adherence, 3 authors (BTM, MT, and BB) compared the respondents' answers to the survey to (1) the multidisciplinary guideline on sciatica ("Richtlijn lumbosacraal radiculair syndroom") 11 and (2) the recommendations on the safety of epidural steroid injections for anesthesiologists in Belgium, Luxemburg, and the Netherlands (World Institute of Pain (WIP) Benelux work group) [13]. The respondents' adherence was rated a 3-point Likert scale ("not in line with guideline," "broadly in line with guideline," or "strictly in line with each guideline").

\section{Ethical Consideration and Funding Statement}

This study was approved by the Institutional Review Board of OLVG Hospital Amsterdam, the Netherlands (January 22, 2020, WO 19.177). Potential respondents were informed about the study objectives as well as the fact that personal information would be protected according to the General Data Protection Regulation. Clicking the link to the online survey served as informed consent. To rule out the possibility of multiple entries, a uniquely generated link was given. There was no funding. 
Table 1. Demographics of participants

\begin{tabular}{|c|c|c|}
\hline & Anesthesiologists (44) & Neurologists (80) \\
\hline Male sex, $n(\%)$ & $33(75)$ & $41(51.2)$ \\
\hline Experience as a specialist, years, $n(\%)$ & Pain specialists & Neurologists $-66 / 80(82.5 \%)$ \\
\hline $0-5$ & $10(23)$ & $16 / 66(24)$ \\
\hline $6-10$ & $9(21)$ & $14 / 66(21)$ \\
\hline $11-15$ & $9(21)$ & $12 / 66(18)$ \\
\hline $15-20$ & $5(11)$ & $5 / 66(8)$ \\
\hline$>20$ & $11(25)$ & $19 / 66(28.8)$ \\
\hline Residents, $n(\%)$ & - & $14 / 80(18)$ \\
\hline Year $0-3^{1}$ & & $10 / 14(71)$ \\
\hline Year 4-6 & & $4 / 14(29)$ \\
\hline \multicolumn{3}{|l|}{ Subspecialty $^{2}, n(\%)$} \\
\hline None/general neurologist & & $16 / 66(24)$ \\
\hline Vascular & & $15 / 66(23)$ \\
\hline MS & & $9 / 66(14)$ \\
\hline Pain/headache ${ }^{3}$ & & $16 / 66(24)$ \\
\hline Cognitive disorders & & $8 / 66(12)$ \\
\hline Movement disorders & & $17 / 66(26)$ \\
\hline Sleep disorders/epilepsy/clinical neurophysiology & & $14 / 66(21)$ \\
\hline Oncology & & $8 / 66(12)$ \\
\hline Neuromuscular disorders & & $6 / 66(9)$ \\
\hline Other ${ }^{4}$ & & $8 / 66(12)$ \\
\hline \multicolumn{3}{|l|}{ Main deployment, $n(\%)$} \\
\hline Academic hospital & $6(14)$ & $8(10)$ \\
\hline Teaching hospital & $23(52)$ & $48(60)$ \\
\hline General hospital & $9(21)$ & $22(28)$ \\
\hline Private practice & $6(14)$ & $2(2)$ \\
\hline
\end{tabular}

\footnotetext{
${ }^{1}$ Year 0 meant the respondent was not a resident (yet). ${ }^{2}$ Some neurologists had multiple subspecialties, leading to a total of $>100 \% .{ }^{3}$ Including "radiculopathy" and "spinal." 4 Including child neurology, ICU, acute neurology, vertigo, infectious neurological diseases, and sports.
}

\section{Results}

\section{Demographic Characteristics}

Ninety-eight neurologists (38\%) and 44 anesthesiologists (59\%) completed the survey. Of them, 80 neurologists met the required criterion of seeing at least 1 patient with sciatica a week. Characteristics of the respondents are presented in Table 1 . In short, $75 \%$ of anesthesiologists (33/44) and $51 \%$ of neurologists (41/80) were male. Of the neurologists, $83 \%(66 / 80)$ were specialists and $18 \%$ $(14 / 80)$ were residents. Neurologists indicated to have different subspecialties, with $24 \%$ (16/66) focusing on pain and/or headache. The majority of both neurologists and anesthesiologists worked at a teaching hospital (60 and $53 \%$, respectively). Neurologists treated on average 4 sciatica patients per week (range; $2-30$ ), whereas anesthesiologists treated on average 11 sciatica patients per week (range; $1-50$ ).

Diagnosis and Treatment of Sciatica: A Dutch Survey

\section{Neurologists: General Questions}

Of the neurologists, $49 \%$ (39/80) reported to follow a protocol, $44 \%$ (17/39) of whom indicated to follow a local protocol and 56\% (22/39) a national guideline.

\section{Diagnosis}

Nine of the 80 neurologists $(11 \%)$ indicated that they always ordered an MRI for acute sciatica patients. Neurologists that only ordered an MRI under specific circumstances $(89 \% ; 71 / 80)$ mostly did so in case of an abnormal neurological examination (65\%; 46/71), including cauda syndrome (see Table 2).

Selective diagnostic nerve blocks are typically performed at a specific, isolated nerve root to determine if that particular nerve root is the source of pain. Most neurologists $(81 \%$; 65/80) considered selective diagnostic nerve blocks useful. Their main reasons for ordering a selective diagnostic nerve blocks were a mismatch be- 
Table 2. Ordering an MRI for patients with acute LSR (symptoms $<8$ weeks)

$\begin{array}{lc}\text { I always order an MRI for these patients because } & 11 \%(9 / 80) \\ \text { 1. I follow the wish/request of the patient } & 33 \%(3 / 9) \\ \text { 2. I need an MRI for confirmation of the diagnosis and reassurance } & 44 \%(4 / 9) \\ \text { 3. I do not want to waste time waiting for an MRI } & 22 \%(2 / 9) \\ \text { 4. An MRI is part of a hernia outpatient clinic } & 22 \%(2 / 9) \\ \text { I order an MRI for these patients under the following circumstances }{ }^{1} & 89 \%(71 / 80) \\ \text { 1. An abnormal neurological exam, including cauda syndrome and/or severe weakness } & 65 \%(46 / 71) \\ \text { 2. A history of malignancy, current B-symptoms, or "higher age"2 } & 28 \%(20 / 71) \\ \text { 3. A longer period of symptoms or severe pain } & 61 \%(43 / 71) \\ \text { 4. An indication for surgery or epidural steroid injection } & 25 \%(18 / 71) \\ \text { 5. On a patient's request } & 27 \%(19 / 71) \\ \text { 6. In case of uncertainty about a patient's diagnosis } & 16 \%(11 / 71) \\ \text { 7. In case of no reaction to pain killers } & 9 \%(6 / 71) \\ \text { 8. Trauma } & 1 \%(1 / 71) \\ \text { 9. Standard MRI as part of a hernia outpatient clinics } & 1 \%(1 / 71) \\ \text { 10. Use of anticoagulants } & 1 \%(1 / 71)\end{array}$

MRI, magnetic resonance imaging. ${ }^{1}$ These numbers do not add up to 71 as respondents were allowed to give

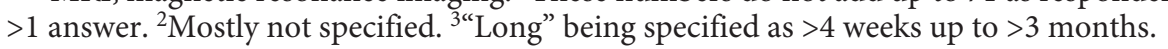

Fig. 1. Answers to the open-ended question "Please elaborate on why you think epidural nerve blocks of the lumbar spine (L2 and below) are safe."

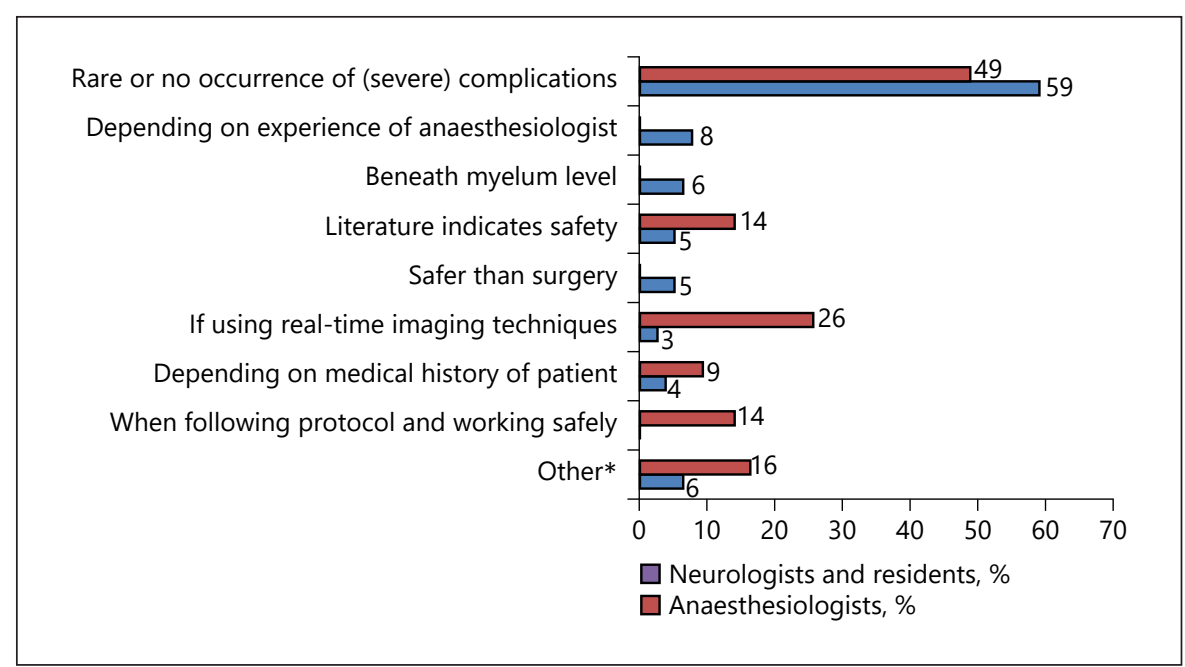

tween patients' clinical symptoms and MRI (24\%; 18/75) or $>1$ level of herniation on the MRI and a doubt about which one is symptomatic $(27 \% ; 20 / 75)$.

\section{Treatment}

Neurologists indicated to prescribe different kinds of oral pain medication, that is, 65\% (52/80) acetaminophen, $76 \%(61 / 80)$ nonsteroidal anti-inflammatory drugs, $59 \%$ (47/80) weak opioid analgesics, 71\% (57/80) strong opioid analgesics, and 45\% (36/80) neuropathic painkillers. Thirty-three percent $(26 / 80)$ of neurologists indicated that they referred $0-20 \%$ of patients to a physiothera- pist, $23 \%(18 / 80)$ indicated to refer $20-40 \%, 16 \%(13 / 80)$ indicated to refer $40-60 \%$, and $19 \%(15 / 80)$ indicated to refer $60-80 \%$. Ten percent $(8 / 80)$ of neurologists indicated that they referred nearly all of their patients to a physiotherapist (i.e., $80-100 \%$ ).

The most important reasons for referring sciatica patients to the Pain Department were pain severity (31\%; $28 / 80$ ) and insufficient pain reduction with oral painkillers $(13 \% ; 29 / 80)$. Five percent of neurologists $(4 / 80)$ reported to never refer patients to the Pain Department. Forty percent $(32 / 80)$ think that epidural steroid injections are effective in $40-60 \%$ of injected patients in terms 
Table 3. Three neurology cases

\begin{tabular}{lccc}
\hline & Case 1 & Case 2 & Case 3 \\
\hline I would perform PROMs & $27 / 80(33 \%)$ & $36 / 80(45 \%)$ & $38 / 80(48 \%)$ \\
NRS & $15 / 27(56 \%)$ & $19 / 36(53 \%)$ & $19 / 38(50 \%)$ \\
VAS & $11 / 27(41 \%)$ & $17 / 36(47 \%)$ & $19 / 38(50 \%)$ \\
Other & $2 / 27(7 \%)$ & $2 / 36(6 \%)$ & $2 / 38(5 \%)$ \\
I would order imaging & $36 / 80(45 \%)$ & $79 / 80(99 \%)$ & $78 / 80(98 \%)$ \\
$\quad$ MRI lumbosacral spine & $36 / 36(100 \%)$ & $79 / 79(100 \%)$ & $78 / 78(100 \%)$ \\
X-ray lumbosacral spine & - & $1 / 79(1 \%)$ & - \\
I would adjust the pain medication & $73 / 80(91 \%)$ & $35 / 80(44 \%)$ & $49 / 80(61 \%)$ \\
I would refer the patient for physical therapy & $25(31 \%)$ & - & $33 / 80(41 \%)$ \\
I would refer the patient to the pain department for ESI & $14 / 80(14 \%)$ & $8 / 80(10 \%)$ & $33 / 80(41 \%)$ \\
I would refer the patient to a neurosurgeon & $2 / 80(3 \%)$ & $26 / 80(33 \%)$ & $23 / 80(29 \%)$ \\
Follow-up is done by the & & & $78 / 80(98 \%)$ \\
Neurology department & $76 / 80(95 \%)$ & $79 / 80(99 \%)$ & $7 / 80(1 \%)$ \\
Pain department & - & - & - \\
GP & $2 / 80(3 \%)$ & - & $1 / 80(1 \%)^{3}$ \\
Other & $2 / 80(3 \%)$ & $1 / 80(1 \%)^{2}$ & $1 / 80$ \\
\hline
\end{tabular}

Numbers and percentages of the answers to some of the questions about the clinical cases for neurologists. NRS, numerical rating scale; VAS, visual analog scale; QBPDS, Quebec Back Pain Disability Scale; HADS, Hospital Anxiety and Depression Scale; PCS, Pain Catastrophizing Scale; MRI, magnetic resonance imaging; ESI, epidural steroid injection; GP, general practitioner; PROMs, patient-reported outcome measures. ${ }^{1}$ QBPDS, HADS), or PCS. ${ }^{2}$ Submitting the patient to the neurology ward. ${ }^{3}$ Neurosurgeon.

of pain reduction $(69 \% ; 55 / 80)$, improvement in functioning $(16 \% ; 13 / 80)$, and reduction in the use of painkillers $(5 \% ; 4 / 80)$.

Of the neurologists, 58\% (46/80) considered epidural steroid injections to be a short-term solution, whereas $15 \%(12 / 80)$ considered them to be a long-term solution. Neurologists considered epidural steroid injections to be safe $(98 \% ; 78 / 80)$, which was mostly based on their personal experience. Other arguments are presented in Figure 1 . Of the neurologists, $60 \%(48 / 80)$ indicated to refer $0-20 \%$ for surgery, $29 \%(23 / 80)$ indicated to refer 20 $40 \%$, and $11 \%(9 / 80)$ indicated to refer $40-60 \%$.

\section{Cases}

An overview of the neurologists' responses in relation to the case studies is given in Table 3 . In summary, the neurologists' responses suggest that in the "acute case" (case 1), neurologists mainly focus on the adjustment of pain medication (91\%), whereas imaging was only considered by $45 \%$ of the respondents. Moreover, there were hardly any referrals to a neurosurgeon (3\%), and epidural corticosteroids were only considered by $14 \%$ of neurologists. For the "subacute case" (case 2), 99\% of respondents would order an MRI. In terms of treatment, $44 \%$ would adjust pain medication, $10 \%$ would refer the pa- tient for an epidural steroid injection, and 33\% would refer for surgery. For the "chronic case" (case 3), almost all of the neurologists (98\%) would order an MRI. In terms of treatment, $62 \%$ would adjust pain medication, $41 \%$ would refer the patient for epidural steroid injections, and $29 \%$ would refer for surgery. In all 3 cases, $95 \%$ of the neurologists would do follow-ups themselves. Patient-reported outcome measures, such as numerical rating scales (NRSs) or visual analog scores (VASs) for pain, would be used by $33-48 \%$ of the respondents.

\section{Anesthesiologists: General Questions}

Twenty-eight of the 44 anesthesiologists (64\%) indicated to follow a protocol, of which 4 (14\%) indicated to follow a local hospital protocol and $24(86 \%)$ a national guideline.

\section{Diagnosis}

When asked whether they considered selective diagnostic nerve root block or mapping to be most useful, $25 \%$ $(11 / 44)$ considered mapping to be most useful, whereas $61 \%(27 / 44)$ considered a selective diagnostic nerve root block to have the highest diagnostic value. Mapping concerns the sensory stimulation of the suspected and adjacent nerve roots and asking the patient for recognizable 


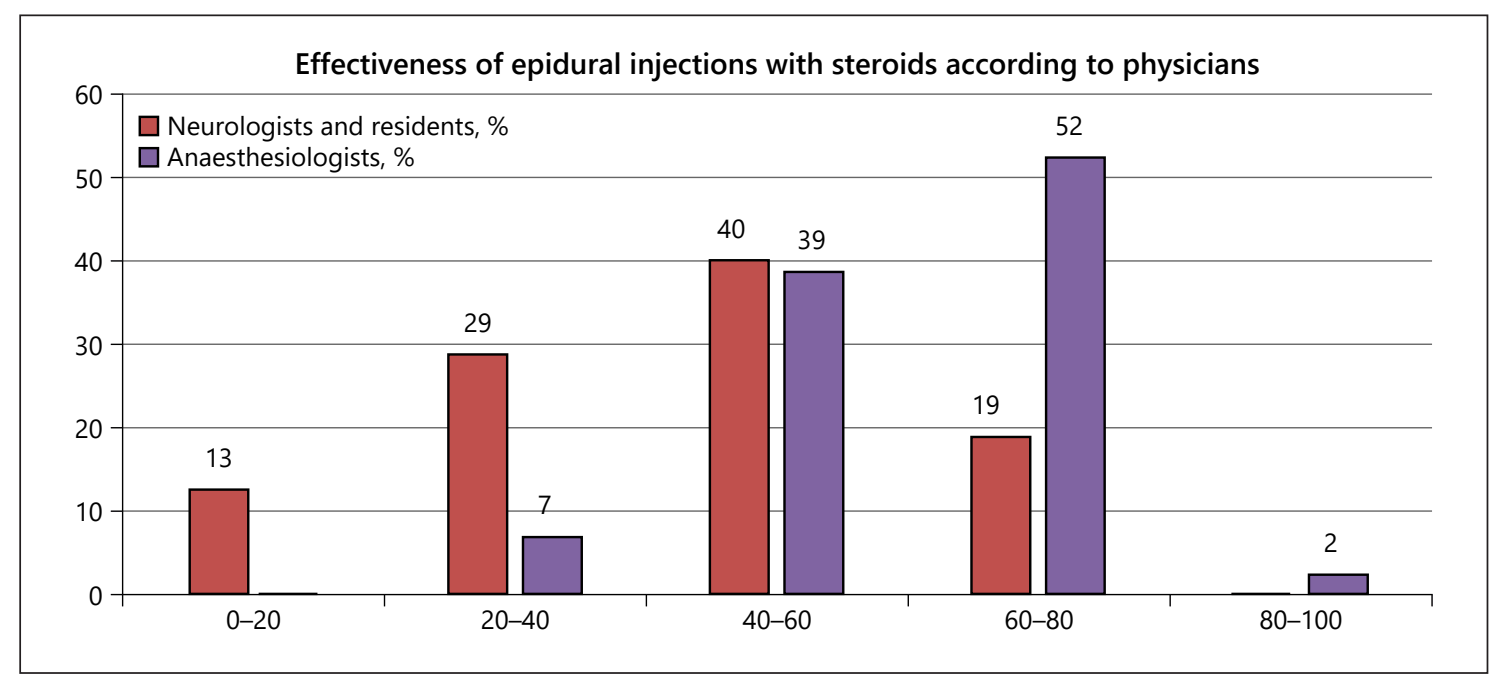

Fig. 2. Answers to the question "In your experience, in which percentage of patients with LR are epidural injections effective?"

paresthesia in their painful area. Twenty-nine (66\%) anesthesiologists typically perform a single selective diagnostic nerve root block, 4(9\%) a double selective diagnostic nerve root blocks, and $11(25 \%)$ answered not to perform selective diagnostic nerve root blocks.

\section{Treatment}

In case of a confirmed lumbar disc herniation, $21 \%$ $(9 / 44)$ of anesthesiologists would perform a single and $78 \%$ (35/44) would perform multiple epidural steroid injections. Thirty-four percent $(11 / 32)$ indicated that they would perform the second injection after 3-6 weeks, $22 \%$ (7/44) after 6 weeks till 3 months, and 44\% (14/44) after 3-6 months. The maximum number of epidural steroid injections within 1 year ranged between 2 and 5 .

Forty-two (96\%) anesthesiologists inject an average amount of $2.6 \mathrm{~mL}(0.75-5.0 \mathrm{~mL})$. Eighty percent $(32 / 44)$ uses a combination of a corticosteroid and a local anesthetic (50\% [22/44] uses lidocaine and 30\% [13/44] bupivacaine). Fifty-two (23/44) of anesthesiologists think that epidural steroid injections are effective in $60-80 \%$ of injected patients. (For all other responses, see Fig. 2.) All of the anesthesiologists indicated that follow-up is done by themselves.

\section{Safety/Complications}

Ninety-eight percent (43/44) of anesthesiologists considered injections of the low lumbar spine to be safe (Fig. 1). The following complications of epidural steroid injections were mentioned: "exacerbation of pain" (36/44)
Table 4. Answers to multiple choice question "In your experience, which complications occur after epidural injections of the lumbosacral spine?"

\begin{tabular}{ll}
\hline Reported complications by anesthesiologists & $\begin{array}{l}\text { Number of } \\
\text { answers, } n(\%)\end{array}$ \\
\hline Exacerbation of pain & $36(82)$ \\
Pain at the injection site & $31(71)$ \\
Vasovagal syncope & $31(71)$ \\
Accidental puncture of the dura & $22(50)$ \\
(Post dural puncture) headache & $18(41)$ \\
Infection (arachnoiditis, [aseptic] meningitis, & \\
$\quad$ or epidural abscess) & $11(25)$ \\
Epidural hematoma & $9(21)$ \\
Fever the night after the procedure & $5(11)$ \\
Persisting numbness & $4(9)$ \\
Nausea and vomiting & $3(7)$ \\
Other ${ }^{1}$ & \\
$\quad$ Flushing & $3(7)$ \\
$\quad$ High blood sugars in diabetic patients & $2(5)$ \\
\hline
\end{tabular}

1 "Other" was an open field.

and $71 \%$ responded "pain at the injection site" or "vasovagal syncope” (31/44) (Table 4$)$.

\section{Cases}

An overview of the anesthesiologists' responses to the 3 case studies is given in Table 5. In summary, for both the "acute case" (case 1) and the "subacute case" (case 2), all respondents would perform an epidural steroid injec- 
Table 5. Anesthesiology cases

\begin{tabular}{|c|c|c|c|}
\hline & Case 1 & Case 2 & Case 3 \\
\hline \multicolumn{4}{|l|}{ Imaging } \\
\hline I would order imaging before invasive pain treatment & $3 / 44(7 \%)$ & $4 / 44(9 \%)$ & $34 / 44(77 \%)$ \\
\hline I would offer the patient treatment with ESI & $44 / 44(100 \%)$ & $44 / 44(100 \%)$ & $25 / 44(66 \%)$ \\
\hline \multicolumn{4}{|l|}{ Treatment with Pulse Radio Frequency (PRF) } \\
\hline I would initially treat the patient with epidural steroids and subsequently consider PRF & $31 / 44(70.5 \%)$ & $29 / 44(66 \%)$ & $24 / 44(55 \%)$ \\
\hline I would not treat this patient with PRF & $7 / 44(16 \%)$ & $9 / 44(21 \%)$ & $7 / 44(16 \%)$ \\
\hline
\end{tabular}

Table 6. Adherence to the most recent multidisciplinary guideline (1) and the WIP Benelux safety recommendations (2)

\begin{tabular}{lll}
\hline Category & According to guideline 1 & According to guideline 2 \\
\hline Neurologists & & \\
Imaging & Broadly in line & $\mathrm{X}$ \\
Diagnostic injections & Not in line & $\mathrm{X}$ \\
Medication & Broadly in line & $\mathrm{X}$ \\
Therapeutic injections & Strictly in line & $\mathrm{X}$ \\
Surgery & Strictly in line & $\mathrm{X}$ \\
Physiotherapy & Broadly in line & Not in line \\
Anesthesiologists & Not line & $\mathrm{X}$ \\
Imaging & Not in line & Broadly in line \\
Diagnostic injections & $\mathrm{X}$ & Strictly in line \\
Therapeutic injections (type) & $\mathrm{X}$ & $\mathrm{X}$ \\
Therapeutic injections (safety) & Not in line & \\
Pulse radiofrequency & & \\
\hline WIP, World Institute of Pain. & & \\
\hline
\end{tabular}

tion. For the "acute presentation without imaging" (case 3), 66\% (33/44) would perform an epidural steroid injection. Pulse radiofrequency blockade was preferred as the first treatment by $9-11 \%$ of the respondents in all 3 cases. If neurologists had already ordered an MRI (as with cases 1 and 2), anesthesiologists would hardly order any additional tests, whereas if neurologists had not performed an MRI (case 3), 68\% (30/44) of the respondents would order an MRI themselves.

\section{Guideline Adherence}

An overview of the neurologists' and anesthesiologists' adherence to the 2 guidelines is shown in Table 6 . Results suggest that neurologists tend to follow the multidisciplinary guideline broadly when it comes to imaging. With regard to selective diagnostic nerve blocks, there seems to be a mismatch, that is, though not recom- mended, diagnostic nerve blocks are generally considered useful in clinical practice. It should be noted, however, that we do not know from our survey how often neurologists refer for selective diagnostic nerve blocks. With regard to medication, the answers of the respondents were broadly in line with the guidelines as neurologists typically follow the World Health Organization (WHO) pain ladder (from the guideline), with the exception of neuropathic pain medication. With regard to referring to physiotherapy, there seems to be a partial mismatch as well, that is, even though the guideline contains a weak recommendation for referring patients to a physiotherapist, only $19 \%$ of neurologists reported to refer $60-80 \%$ of patients to a physiotherapist. With regard to epidural steroid injections, the guideline states that "epidural steroid injections can be considered in sciatica patients in case of severe pain despite pain medication," a 
recommendation that is rather strictly followed. Disc surgery is recommended by the guideline in case of a herniated disc causing severe pain, prolonged symptoms, or neurological deficits, for example, cauda syndrome: this is also strictly followed.

For anesthesiologists, we see that the WIP recommendations on the safety of epidural injections are strictly followed. This does not apply to imaging: even though imaging is considered necessary before an epidural injection, about $1 / 3$ of the anesthesiologists do not do so in daily practice (see case study 3 ). With regard to selective diagnostic nerve blocks, there seems to be a mismatch between the guideline and the opinion of most anesthesiologists. That is, though selective diagnostic nerve blocks are not recommended, they are generally considered useful. With regard to the type and quantity of the injected fluids, there is considerable variation between the different injection fluids that are used (therefore "broadly in line"). With regard to pulsed radiofrequency, we concluded that the results are not in line with multidisciplinary guideline: although not recommended by the multidisciplinary guideline in the treatment of (sub)acute sciatica, $9-11 \%$ of our the respondents would use pulse radiofrequency in the acute phase of sciatica.

\section{Discussion}

The results of our survey suggest that 2 patterns of diagnosis and treatment can be distinguished ("established facts"): (a) neurologists diagnose their sciatica patients primarily with an MRI, that is, ordered in case of severe pain, prolonged symptoms, or presence of symptoms and signs that suggest an etiology other than a herniated disc. Selective (diagnostic) nerve blocks are considered useful. Patients are treated with a wide variety of medication first and referred for epidural steroid injections as a second step if they fail to respond to pain medication. Patients may also be referred to a physiotherapist with the aim to improve movement and the provision of interventions against kinesiophobia. As a third step, patients will be referred to a surgeon, increasing from 3\% at 3 weeks (painful sciatica not responsive to medication) to $29 \%$ at 4 months. (b) Anesthesiologists treat $100 \%$ of their sciatica patients with epidural corticosteroids upon referral from the neurologist. This percentage drops to $66 \%$ if no imaging has been performed before. There is considerable variation in the type and quantity of the injection fluid and the number of injections when performing epidural steroid injections. The anesthesiologists' most reported side effects of these injections were in accordance with international literature $[14,15]$. Pulse radiofrequency is mostly applied as a secondary step, if epidural steroid injections lack a good long-term response. A minority (9-11\%) of the anesthesiologists indicated to use pulse radiofrequency as a primary treatment in the acute phase of sciatica ( $<3$ months). Selective nerve root blocks are considered useful. This applies to a lesser extent to mapping, which is a relatively new diagnostic tool $[16,17]$.

Our survey coincides with the launch of the new Dutch multidisciplinary guideline on sciatica [11] Therefore, it is interesting to see how well clinicians currently follow these guidelines. In their 2018 article that was part of the Lancet "Back pain series," Foster et al. [18] concluded that "despite many clinical guidelines with similar recommendations for the management of low back pain, the gap between evidence and practice is pervasive." Our survey is in line with this when it comes to imaging before an epidural injection, referral to physiotherapy, and pulse radiofrequency in the acute stage ( $<3$ months). That is, these treatments and/or diagnostic procedures are used in daily practice, despite a poor (physiotherapy) or moderate recommendation (pulse radiofrequency) to apply them or because they were not performed, despite being recommended (imaging before epidural steroid injection). The same applies to selective diagnostic nerve blocks: though not recommended, these are considered useful. Moreover, there is partial discordance ("broadly followed") between daily practice and the guidelines when it comes to medication and imaging by neurologists. For medication, the new multidisciplinary guideline advices to use the WHO pain ladder [19]. We saw that the ladder is used but that neurologists also prescribe neuropathic pain medication that lacks good evidence (e.g., pregabalin) [20]. It should be noted that the guideline advices MRIs only in selected cases, including patients with severe pain irresponsive to pain medication (and therefore candidates for epidural injection or surgery) or patients with neurological deficits (cauda syndrome and severe paresis < Medical Research Council (MRC) 4) that are candidates for an urgent surgical procedure. This advice is followed by most of the neurologists (89\%), but to a lesser extent by anesthesiologists performing an epidural steroid injection (66\%). For other domains (including epidural steroid injections, surgery and safety measures), there is good accordance between practice and guidelines. It is noteworthy that contrary to only a small but significant short-term ( $<3$ months) effect for leg pain of epidural corticosteroids versus placebo $(<1$ point on a 10 
points pain scale) shown by recent systematic reviews and meta-analyses [21-24], epidural injections are considered rather effective by both neurologists and anesthesiologists (Fig. 2). However, in daily practice, epidural corticosteroid injections are used only in case of ineffective pain medication (as recommended).

Our survey has several strengths, including its combination of general questions and case studies, which provide valuable insight into the way neurologists and anesthesiologists think. Moreover, surveys on sciatica have been published before, but those were restricted to surgeons $[25,26]$, whereas ours addresses neurologists and anesthesiologists.

This survey also has some limitations. First, the use of semi-structured interviews would have provided more detailed information about the respondents' clinical reasoning than a survey. Second, there might be some level of selection bias. As we approached respondents primarily through residency program directors and members of the Pain Section of the Dutch Society of Neurology, this survey was mainly focused on hospital-based specialists, and therefore, specialists working in private practice might be underrepresented (see Table 2). On the other hand, it is important to take into account that in the Netherlands, the majority of neurologists and anesthesiologists work in a hospital setting and only very few work in private practices. Therefore, for the Dutch situation, this survey looks to be an adequate representation. Another factor that needs attention is that the kind of specialists treating sciatica patients might differ between countries. In the Netherlands, the overwhelming majority of sciatica patients in secondary care is treated by neurologists and anesthesiologists (i.e., 84\% [27]). The remainder is treated by orthopedic surgeons and a few other specialists such as rheumatologists $(<2 \%)$. In other countries, such as the USA, however, a large share of sciatica patients are treated by the latter. Hence, the results of our survey might not be relevant to all other healthcare systems. Third, the number of respondents was somewhat limited, and consequently, our data may not be generalizable to all neurologists and anesthesiologists in the Netherlands. However, the number of surveyed physicians and the response rate were almost equal to similar types of surveys $[28,29]$.

Note that this survey was finished just before the arrival of the COVID-19 pandemic in the Netherlands in March 2020, which had huge implications for the Dutch healthcare sector. Among others, there were less opportunities to see patients in the outpatient setting because of limited availability of doctors and resources and because of safety issues, for example, epidural steroids were not recommended to reduce the risk of COVID-19 infection [30].

Based on the current findings ("novel insight"), we think that various areas of (partial) discordance between daily practice and guidelines are topics for further research (e.g., selective nerve root blocks or medication). Moreover, we think that the use of patient-reported outcome measures should be implemented more broadly to focus on a patient's individual health goals.

\section{Conclusion}

Neurologists treat sciatica patients initially with pain medication and physiotherapy, followed by epidural steroid injections and referral for surgery if patients fail to respond to conservative treatment. Anesthesiologists treat sciatica patients with steroid injections or may perform a selective nerve root block or mapping in case of doubt about the origin of radicular pain. Imaging, medication, referral to physiotherapy, and pulse radiofrequency in the acute stage ( $<3$ months) are considered topics of further research. This also applies to selective nerve root blocks. Imaging before epidural steroid injections is not always performed but should be from the perspective of safety.

\section{Acknowledgements}

The authors acknowledge the help of all participants of the survey.

\section{Statement of Ethics}

This research complies with the guidelines for human studies and was conducted ethically in accordance with the World Medical Association Declaration of Helsinki. This study was approved by the Institutional Review Board of OLVG Hospital Amsterdam, the Netherlands (January 22, 2020, WO 19.177). Potential respondents were informed about the study objectives as well as the fact that personal information would be protected according to the General Data Protection Regulation. Clicking the link to the online survey served as informed consent.

\section{Conflict of Interest Statement}

There are no competing interests. 


\section{Funding Sources}

No funding was obtained for this study.

\section{Author Contributions}

R.O. and B.T.M. conceived the survey. R.O., H.W., J.W.K., and B.T.M. contributed to the design of the survey J.V.D. oversaw the design of the statistical analyses. B.T.M. and C.O. analyzed the raw data. T.F. contributed to the methods sections. B.B., M.T., and B.T.M. compared the survey outcomes to the current guidelines. B.T.M. and C.O. drafted the manuscript. All authors contributed to the manuscript and approved the final version for publication.

\section{Availability of Data and Material}

The raw data generated and/or analyzed during the current study are not publicly available due to institution policy but are available from the corresponding author on reasonable request.

\section{Consent for Publication}

Consent for publication is not needed for this kind of study because only anonymous data are used.

\section{Author Informations}

B.T.M., MD, neurologist and PhD student, OLVG Teaching Hospital and Amsterdam Movement Sciences Research Institute; C.O., medical student OLVG Teaching Hospital; T.F., neurology resident OLVG Teaching Hospital; B.B., MD PhD neurologist and pain specialist, Maastricht University Medical Center; M.T., MD anesthesiologist Rijnstate Hospital, Arnhem; J.V.D. PhD Department of Epidemiology and Data Science, Amsterdam Movement Sciences Research Institute, Amsterdam UMC, Location VUMC; J.W.K., MD PhD, anesthesiologist Rijnstate Hospital, Arnhem; R.O., PhD, professor, Department of Epidemiology and Data Science, Amsterdam Movement Sciences Research Institute, Amsterdam UMC, Location VUMC, and Department of Health Sciences, Faculty of Science, Vrije Universiteit, Amsterdam Movement Sciences Research Institute; H.W., MD PhD, neurologist at OLVG Teaching Hospital and professor of cognitive neurology at Vrije Universiteit Amsterdam.

\section{References}

1 Ropper AH, Zafonte RD. Sciatica. N Engl J Med. 2015 Mar 26;372(13):1240-8.

2 Porchet F, Wietlisbach V, Burnand B, Daeppen K, Villemure JG, Vader JP. Relationship between severity of lumbar disc disease and disability scores in sciatica patients. Neurosurgery. 2002;50(6):1253-60.

3 Spijker-Huiges A, Groenhof F, Winters JC, van Wijhe M, Groenier KH, van der Meer K. Radiating low back pain in general practice: incidence, prevalence, diagnosis, and longterm clinical course of illness. Scand J Prim Health Care. 2015 Mar;33(1):27-32.

4 Konstantinou K, Dunn KM, Ogollah R, Lewis M, van der Windt D, Hay EM. ATLAS Study Team Prognosis of sciatica and back-related leg pain in primary care: the ATLAS cohort. Spine J. 2018 Jun;18(6):1030-40.

5 Atlas SJ, Deyo RA, Keller RB, Chapin AM, Patrick DL, Long JM, et al. The Maine Lumbar Spine Study, part II. 1-year outcomes of surgical and nonsurgical management of sciatica. Spine. 1996 Aug 1;21(15):1777-86.

6 Available from: https://www.nhg.org/standaarden/volledig/nhg-standaard-lumbosacraal-radiculair-syndroom-lrs

7 Available from: https://www.zorginstituutnederland.nl/publicaties/rapport/ 2020/03/16/analyse-info-lage-rug

8 Virk SS, Phillips FM, Khan SN. Factors affecting utilization of steroid injections in the treatment of lumbosacral degenerative conditions in the United States. Int J Spine Surg. 2018;12(2):139-48.
9 Stochkendahl MJ, Kjaer P, Hartvigsen J, Kongsted A, Aaboe J, Andersen M, et al. National clinical guidelines for non-surgical treatment of patients with recent onset low back pain or lumbar radiculopathy. Eur Spine J. 2018;27(1):60-75.

10 Koes BW, van Tulder MW, Peul WC. Diagnosis and treatment of sciatica. BMJ. 2007; 334(7607):1313-7.

11 Available from: https://richtlijnendatabase. nl/richtlijn/lumbosacraal_radiculair_syndroom/lumbosacraal_radiculair_syndroom_-_startpagina.html

12 Eysenbach G. Improving the quality of web surveys: the checklist for reporting results of internet E-surveys (CHERRIES). J Med Internet Res. 2004 Jul-Sep;6(3):e34.

13 Van Boxem K, Rijsdijk M, Hans G, de Jong J, Kallewaard JW, Vissers K, et al. Safe Use of epidural corticosteroid injections: recommendations of the WIP Benelux Work Group. Pain Pract. 2019;19(1):61.

14 Abram SE, O'Connor TC. Complications associated with epidural steroid injections. Reg Anesth. 1996;21(2):149-62.

15 McGrath JM, Schaefer MP, Malkamaki DM. Incidence and characteristics of complications from epidural steroid injections. Pain Med. 2011;12(5):726-31.

16 Hunter CW, Yang A, Davis T. Selective radiofrequency stimulation of the dorsal root ganglion (DRG) as a method for predicting targets for neuromodulation in patients with post amputation pain: a case series. Neuromodulation. 2017;20(7):708-18.
17 Van Boxem K, Huntoon M, Van Zundert J, Patijn J, van Kleef M, Joosten EA. Pulsed radiofrequency: a review of the basic science as applied to the pathophysiology of radicular pain: a call for clinical translation. Reg Anesth Pain Med. 2014;39(2):149-59.

18 Foster NE, Anema JR, Cherkin D, Chou R, Cohen SP, Gross DP, et al. Prevention and treatment of low back pain: evidence, challenges, and promising directions. Lancet. 2018 Jun 9;391(10137):2368-83.

19 Available from: https://www.who.int/cancer/ palliative/painladder/en/.

20 Mathieson S, Maher CG, McLachlan AJ, Latimer J, Koes BW, Hancock MJ, et al. Trial of pregabalin for acute and chronic sciatica. N Engl J Med. 2017;376(12):1111-20.

21 Huygen F, Kallewaard JW, van Tulder M, Van Boxem K, Vissers K, van Kleef M, et al. "Evidence-based interventional pain medicine according to clinical diagnoses": update 2018. Pain Pract. 2019;19(6):664-75.

22 Lewis RA, Williams NH, Sutton AJ, Burton K, Din NU, Matar HE, et al. Comparative clinical effectiveness of management strategies for sciatica: systematic review and network metaanalyses. Spine J. 2015;15(6):1461-77.

23 Pinto RZ, Maher CG, Ferreira ML, Hancock M, Oliveira VC, McLachlan AJ, et al. Epidural corticosteroid injections in the management of sciatica: a systematic review and meta-analysis. Ann Intern Med. 2012;157(12): 865-77. 
24 Oliveira CB, Maher CG, Ferreira ML, Hancock MJ, Oliveira VC, McLachlan AJ, et al. Epidural corticosteroid injections for lumbosacral radicular pain. Cochrane Database Syst Rev. 2020 Apr 9;4(4):CD013577.

25 Arts MP, Peul WC, Koes BW, Thomeer RT. Leiden-The Hague Spine Intervention Prognostic Study (SIPS) Group. Management of sciatica due to lumbar disc herniation in the Netherlands: a survey among spine surgeons. J Neurosurg Spine. 2008;9(1):32-9.
26 Gadjradj PS, Arts MP, van Tulder MW, Rietdijk WJR, Peul WC, Harhangi BS. Management of symptomatic lumbar disk herniation: an international perspective. Spine. 2017; 42(23):1826-34.

27 Available from: https://www.zorginstituutnederland.nl/werkagenda/publicaties/rapport/2020/04/01/zorggebruik-lage-rugtweede-lijn

28 Overdevest GM, Moojen WA, Arts MP, Vleggeert-Lankamp CL, Jacobs WC, Peul WC. Management of lumbar spinal stenosis: a survey among Dutch spine surgeons. Acta Neurochir. 2014 Nov;156(11):2139-45.
29 Chagnas MO, Poiraudeau S, Lefèvre-Colau MM, Rannou F, Nguyen C. Diagnosis and management of lumbar spinal stenosis in primary care in France: a survey of general practitioners. BMC Musculoskelet Disord. 2019 Sep 14;20(1):431.

30 Shanthanna H, Strand NH, Provenzano DA, Lobo CA, Eldabe S, Bhatia A, et al. Caring for patients with pain during the COVID-19 pandemic: consensus recommendations from an international expert panel. Anaesthesia. 2020; 75(7):935-44. 